\title{
Neurofuzzy approach to process parameter selection for friction surfacing applications
}

\author{
V.I. Vitanov ${ }^{\mathrm{a}, *}$, I.I. Voutchkov ${ }^{\mathrm{b}}$, G.M. Bedford ${ }^{\mathrm{c}}$ \\ ${ }^{a}$ Building 30, School of Industrial and Manufacturing Sciences, Cranfield University, Cranfield, Bedfordshire, MK43 OAL, UK \\ ${ }^{\mathrm{b}}$ CEDC, School of Engineering Sciences, University of Southampton, Highfield, Southampton SO17 1BJ, UK \\ ${ }^{\mathrm{c}}$ Department of Mechanical and Manufacturing Engineering, University of Portsmouth, Anglesea Road, Anglesea Building, \\ Portsmouth PO1 3DJ, UK
}

Received 31 July 2000; accepted in revised form 1 March 2001

\begin{abstract}
Friction surfacing is an advanced manufacturing process, which has been successfully developed and commercialised over the past decade. The process is used for corrosion and wear resistant coatings and for reclamation of worn engineering components. At present, the selection of process parameters for new coating materials or substrate geometries experimentally requires lengthy development work. The major requirement is for the flexibility to enable rapid changes of process parameters in order to develop new applications, with variations of materials and geometries in a cost effective and reliable manner. Further improvement requires development of appropriate mathematical models of the process, which will facilitate the introduction of optimisation techniques for efficient experimental work as well as the introduction of real time feedback adaptive control. This paper considers the use of combined artificial intelligence and modelling techniques. It includes a new frame of a Neurofuzzy-model based Decision Support System - FricExpert, which is aimed at speeding up the parameter selection process and to assist in obtaining values for cost effective development. Derived models can then be readily used for optimisation techniques, discussed in our earlier work. (c) 2001 Elsevier Science B.V. All rights reserved.
\end{abstract}

Keywords: $[\mathrm{X}][\mathrm{C}]$ Friction surfacing; [C] Hardfacing; Artificial intelligence

\section{Introduction}

During the past decade the friction surfacing process has become well established with a number of commercial applications. However, the existing models explaining the major relationships between process parameters are still generic. They are based on empirical rules and theoretical assumptions that account for a limited number of cases of current commercial interest. Many of these assumptions are implicit and have not been tested by using appropriate analysis and design of experiments. Consequently, there is no method of determining the accuracy and sensitivity when changes in

\footnotetext{
* Corresponding author.
}

the process parameters are made [1,2]. Research so far [3-8] has revealed that in friction surfacing the mechtrode $^{\mathrm{TM}}$ force $(F)$, mechtrode rotation speed $(N)$ and substrate traverse speed $(V)$ are of critical importance for the final quality of the coating and bond. In the present study, three state variables were considered that reflect coating quality and, so far have been the subject for optimisation, and in this context a target for process parameter selection. These are coating thickness $\left(C_{t}\right)$, coating width $\left(C_{w}\right)$, and coating bond strength $\left(C_{b s}\right)$. The optimisation procedure considered in this study involved:

- appropriate set-up for in-process precision measurement of temperature, torque, bonding time, spindle rotation speed and force; 
- estimation of correlation between process parameters $V, F, N$, and coating quality state variables $C_{b s}, C_{t}$ and $C_{w}$; and

- development of a FricExpert decision support system to utilise force $(F)$, mechtrode rotation speed $(N)$, and substrate traverse speed $(V)$, as well as temperature $(T)$, torque $(M)$, and bonding time $\left(t_{b}\right)$, to achieve the desired values for coating thickness $\left(C_{t}\right)$, coating width $\left(C_{w}\right)$, and bond strength $\left(C_{b s}\right)$.

\section{Experimental method}

\subsection{Materials and geometry}

The importance of torque, temperature and bonding time for obtaining coatings with desirable quality parameters is identified in [8]. The significance of these factors has also been confirmed through performing more than 1300 friction surfacing screening experiments in the surface engineering laboratory at the University of Portsmouth, using different materials and geometries for the mechtrodes and substrates, Fig. 1. Several different types of stainless steel mechtrodes were used $(303,304,316,416,431)$, ranging in diameter from 3 to $8 \mathrm{~mm}$.

\subsection{Temperature and bonding time}

Because of the nature of the in-process measurements of the coating and the mechtrode/coating/substrate interface temperatures, a non-contact IR pyrometer, manufactured by IMPAC Electronic, was used. The accuracy of measurement is approximately $0.3 \%$ of the measured value. Two lenses were used, with focus distances of 80 and $250 \mathrm{~mm}$, with a spot size diameter of 0.3 and $0.5 \mathrm{~mm}$, respectively. The sampling rate was $10^{3}$ measurements / s enabling accurate determination of bonding times for each coating cycle. Fig. 2 shows a cross-section of the deposit and directions of tempera- ture measurement using the IR pyrometer. The experimental results were automatically recorded into a purpose-designed database. This approach significantly reduced set-up time and running costs for the friction surfacing experiments.

Bonding time is defined as the duration when the diameter of the heat generation area (bonding area) passes entirely over a given point on the substrate. As shown in Fig. 3a, the bonding area is less than the surface specified by the mechtrode diameter. It has been estimated that the axial diameter of the bonding area is approximately $6 / 7$ of its tangential diameter, which is equal to the mechtrode diameter, so that

$d_{b}=0.875 \times M_{d}$,

where $M_{d}$ is the mechtrode diameter. The bonding time is then defined as:

$t_{b}=\frac{0.875 M_{d}}{V}$

where $V$ is the traverse speed.

Fig. $3 b$ shows the bonding time for the most used mechtrode diameters and substrate speeds.

Longer bonding time would logically mean better bonding, since there is more time for the process to occur and complete. However, the heat energy flux, which is generated during this bonding time, has to be balanced, because if too much, it might have a negative effect on the quality of coating. The easiest way to control the energy flux is by altering the bonding time. Furthermore, experiments have shown that low values of $V$, are difficult to achieve.

\subsection{Torque and force}

Torque was measured using a piezoelectric sensor manufactured by Kistler Instruments with a measuring range for force of $0-14000 \mathrm{~N}$ and $\pm 20000 \mathrm{Ncm}$ for torque. The sensitivity of the equipment is $\mathrm{pC} / \mathrm{N}=$ -2.03 and $\mathrm{pC} / \mathrm{Ncm}=1.66$. The acquired sets of data were stored in a database by using multifunction $\mathrm{I} / \mathrm{O}$

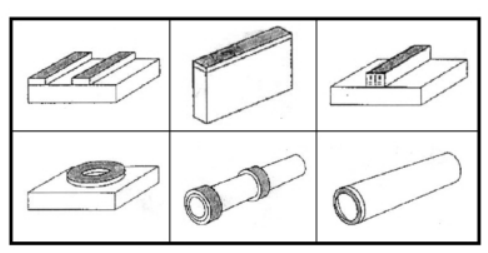

\begin{tabular}{|c|l|l|l|l|}
\hline Substrate & $\mathrm{Al}$ & MS & SS & $\mathrm{Ti}$ \\
\hline Mechtrode & & & & \\
\hline Aluminium & & & & \\
\hline Mild Steel & & & & \\
\hline $\begin{array}{c}\text { Stainless } \\
\text { steel }\end{array}$ & & & & \\
\hline $\begin{array}{c}\text { High speed } \\
\text { S }\end{array}$ & & & & \\
\hline $\begin{array}{c}\text { Stellite 6, } \\
12\end{array}$ & & & & \\
\hline
\end{tabular}

Fig. 1. Typical substrate geometries and substrate/mechtrode material combinations for friction surfacing applications. 
a)

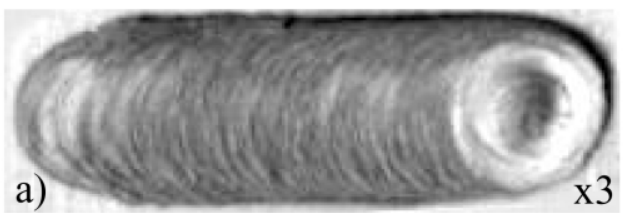

b)

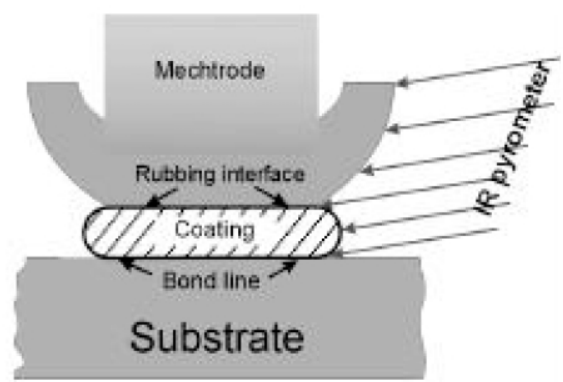

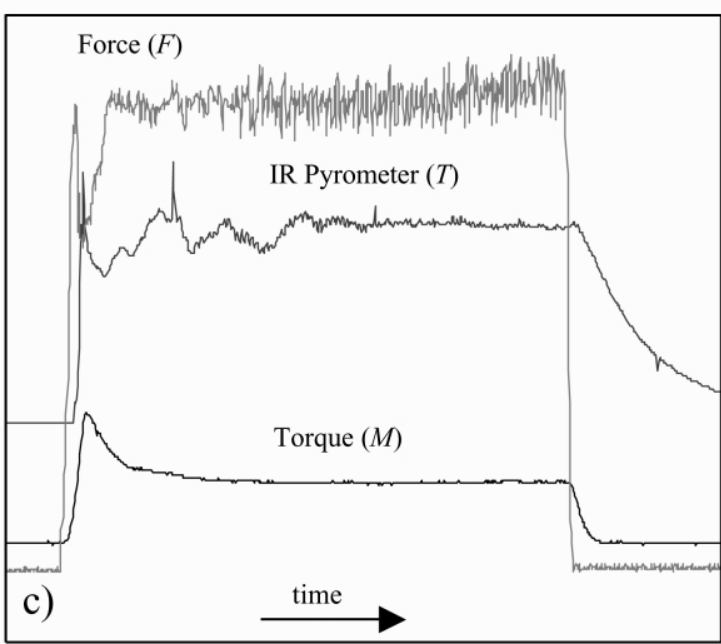

Fig. 2. (a) Plan view of coating, (b) temperature measurements, and (c) process parameters. board (AT-MIO-16E-10) from National Instruments capable of data acquisition at a rate of 100000 samples $\mathrm{s}^{-1}$. LabVIEW application software was used to automate the data acquisition process. Examples of data acquisition and condition monitoring software are shown in Fig. 4.

\subsection{Bond metallography and strength}

Cross-sections of coatings were examined in the aspolished state to determine the quality and width of the bond, and the amount of unbonded undercut at the edges of the coating. Bond strengths were determined by a simple push-off test, although more sophisticated testing based on a fracture mechanics approach is currently being developed. The metallography of a cross-section of a well-formed friction surfaced coating is shown as in Fig. 5a,b. This clearly illustrates the undercut at the edge which is an inherent feature of the process. The optimisation process essentially extends the width of good bond and minimises the undercut at the edges. Materials used in these illustrations are 316 stainless steel coatings on mild steel.

\section{General concept of FricExpert decision support system}

The development process of the FricExpert Decision Support System comprises the following key stages:

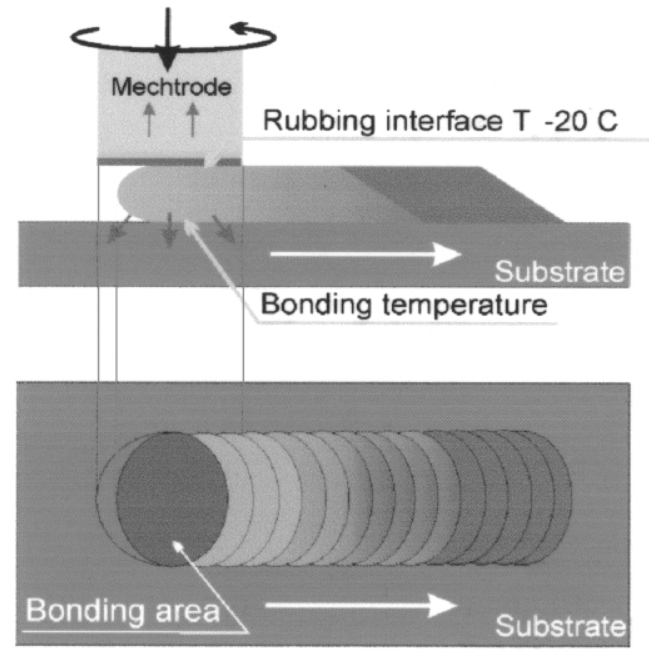

a) Bonding area

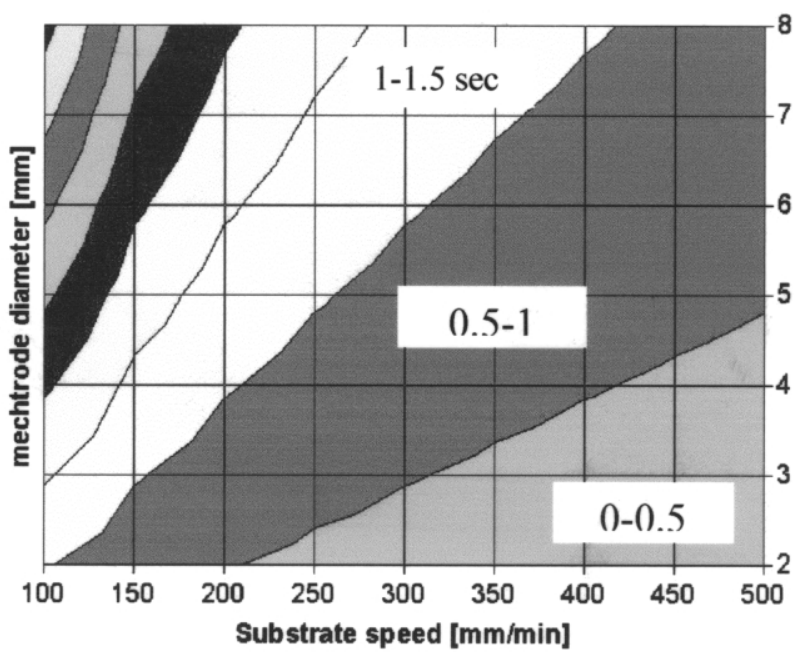

b) Bonding time

Fig. 3. (a), (b) Bonding parameters. 


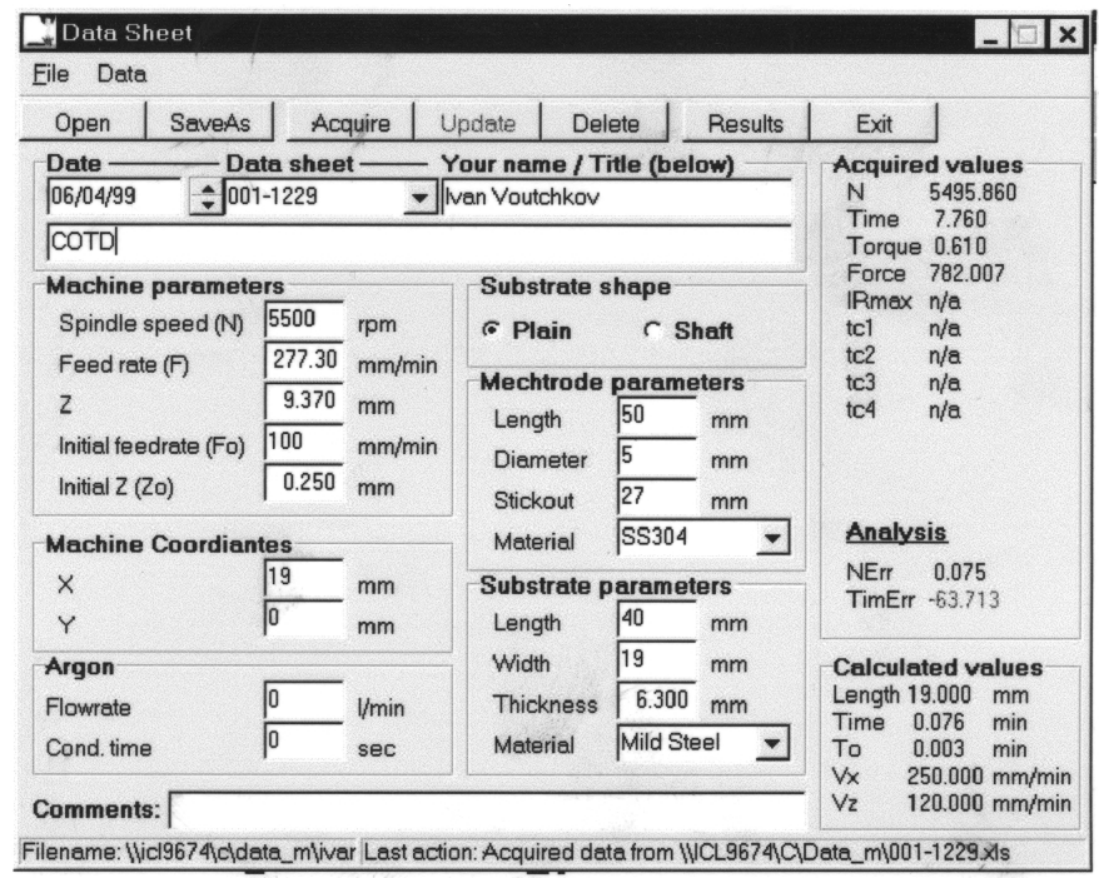

Fig. 4. Screen shot of data collection and storage software.

- establishment of the relationships between controllable, observable and quality parameters; and

- development of the inference mechanism.

\subsection{Relationship between process parameters and coating state variables}

Fig. 6 is a schematic of the adopted experimental approach and indicates dependencies between process parameters $V, F$ and $N$, and coating state variables $C_{b s}, C_{t}$ and $C_{w}$. To initially establish these relationships the bonding time, torque and temperature have been measured followed by regression and neural net- work analysis to confirm the existence of relationships and to establish the types of function. Fig. 7 shows an example of the effect of mechtrode feed rate on the deposit width. Similar relationships have been established for the rest of the process parameters and coating state variables. The same procedure has been repeated for $M, t_{b}$ and $T$, and coating state variables $C_{b s}, C_{t}$ and $C_{w}$. But this time $M, t_{b}$ and $T$ have been regarded as dependent variables. As a result of this analysis, functional relationships between major parameters and state variables have been obtained as shown in Fig. 8. These results form a foundation for reverse process designs. On the basis of detailed measurements the following rules were derived:

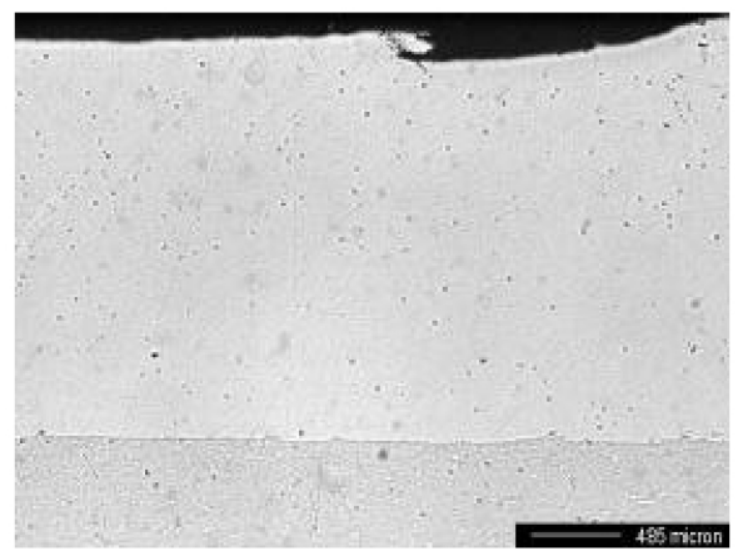

a) middle section

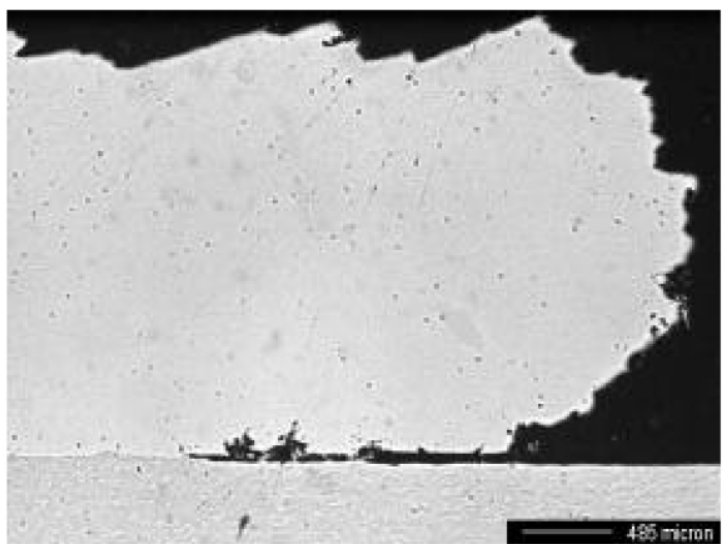

b) undercut

Fig. 5. (a), (b) Cross-sections showing coating/substrate interface, as polished $(\times 50)$. 


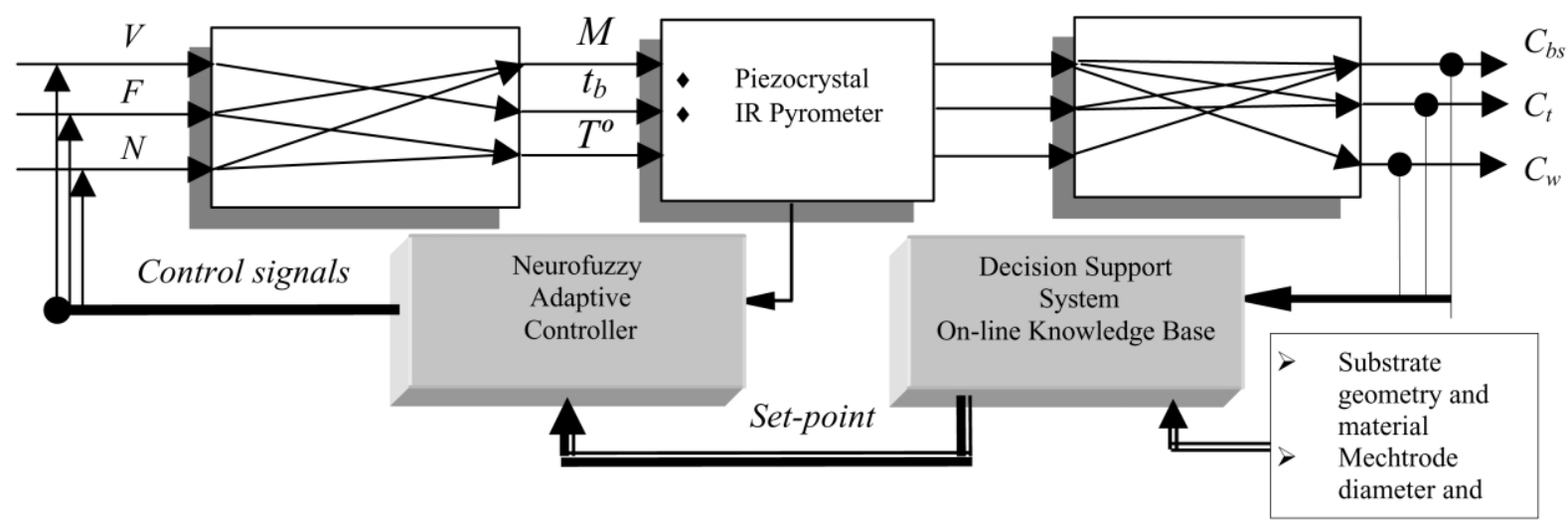

Fig. 6. Schematic representation of experimentally established relationships between controllable, observable and quality parameters in the friction surfacing process.

- increasing force increases proportionally the bond strength;

- increasing force reduces proportionally the coating thickness;

- increasing traverse speed reduces proportionally the coating thickness;

- increasing traverse speed has a second order relationship to the bond strength;

- low values of $V$ make the coating thicker;

- an increase of coating thickness weakens the bond;

- high traverse speed reduces the coating thickness, and the bonding time, resulting in reduced bond strength; and

- the traverse speed has its optimum value around the centre of gravity of the trapezium.
Bond quality is also related to input parameters.

- The higher the mechtrode force, the less the undercut.

- The faster the substrate movement the less the bonded area, the more the undercut.

\subsection{Inference mechanism}

The experimental results have been transformed into fuzzy membership functions and the above principles have been developed further into fuzzy logic rules

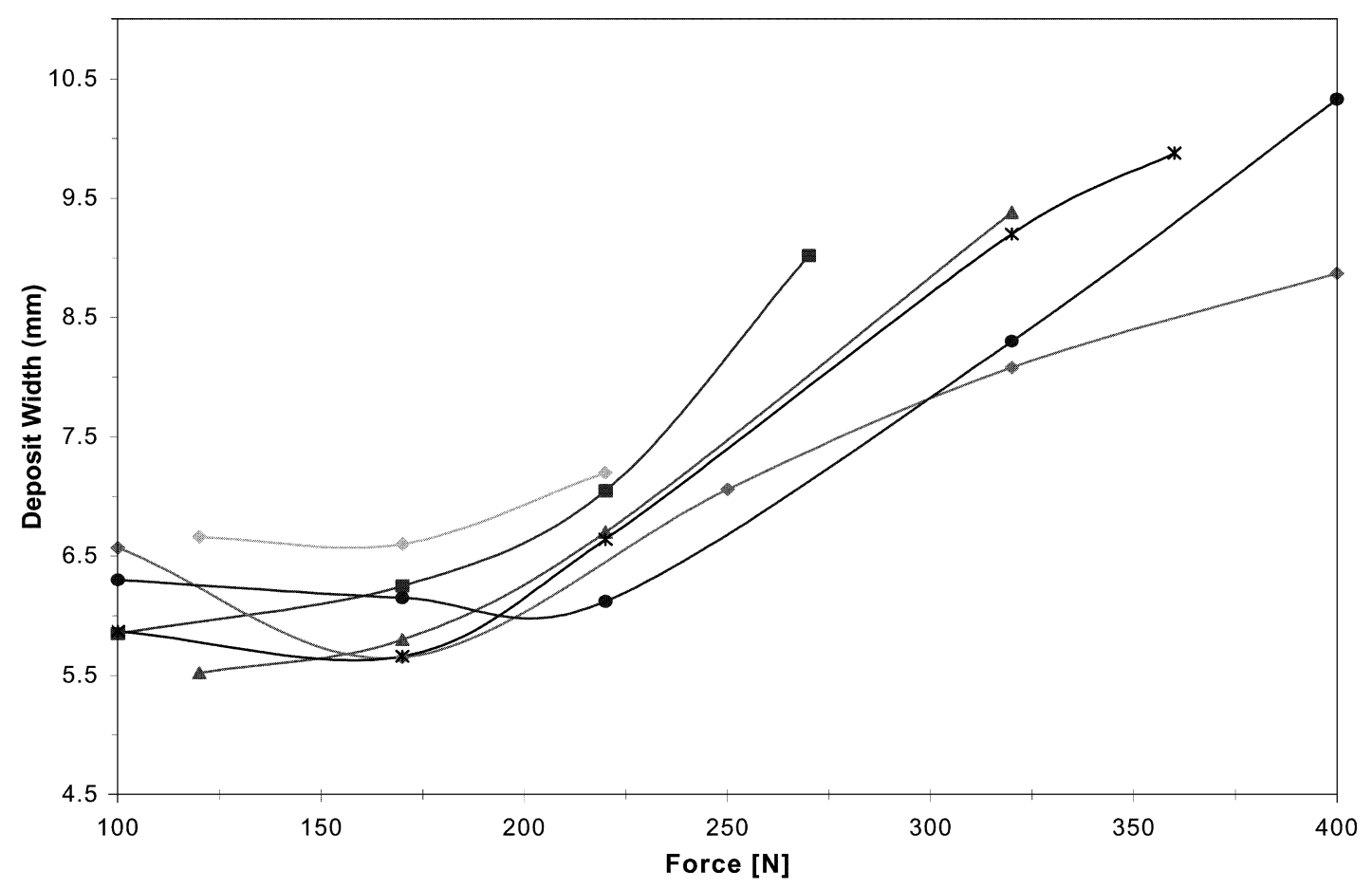

Fig. 7. The effect of the mechtrode force on the deposit width - mechtrode material - stainless steel, diameter $=5 \mathrm{~mm}$. 

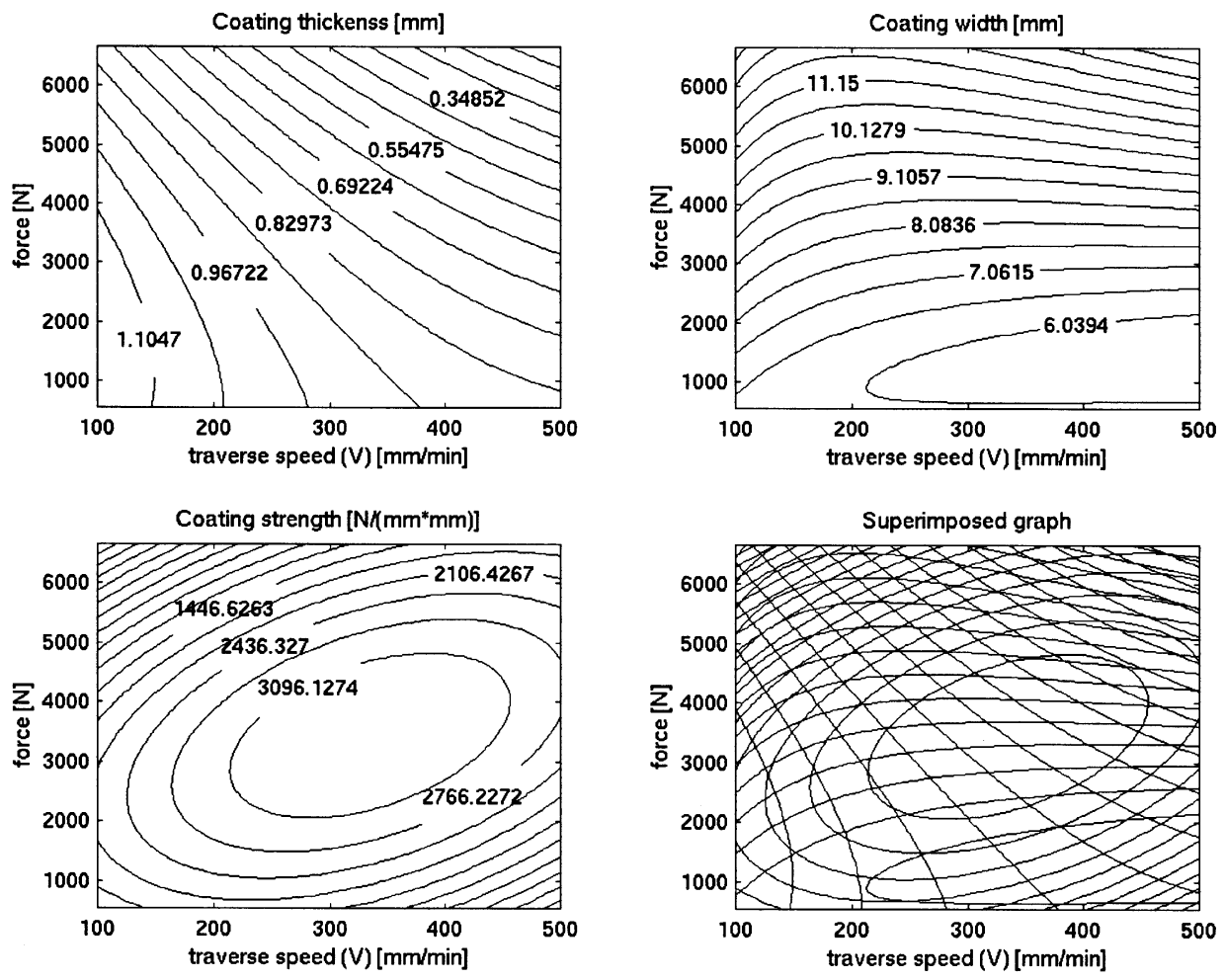

Fig. 8. Functional relationships between major process parameters and coating state variables.

[9-13] that are built into FricExpert's inference engine. In the current approach, presented schematically in Fig. 9, the decision support module selects appropriate values of the process parameters, traverse speed and force in order to obtain a desired value for the coating thickness. The bell-shaped curves represent the mem- bership functions. When a value for the force and speed is set, its membership is determined and passed onto the logic rules relating it to the thickness. Actual value for thickness is then obtained using logical multiplication and defuzzyfication procedures.

Using the knowledge of previously recorded runs
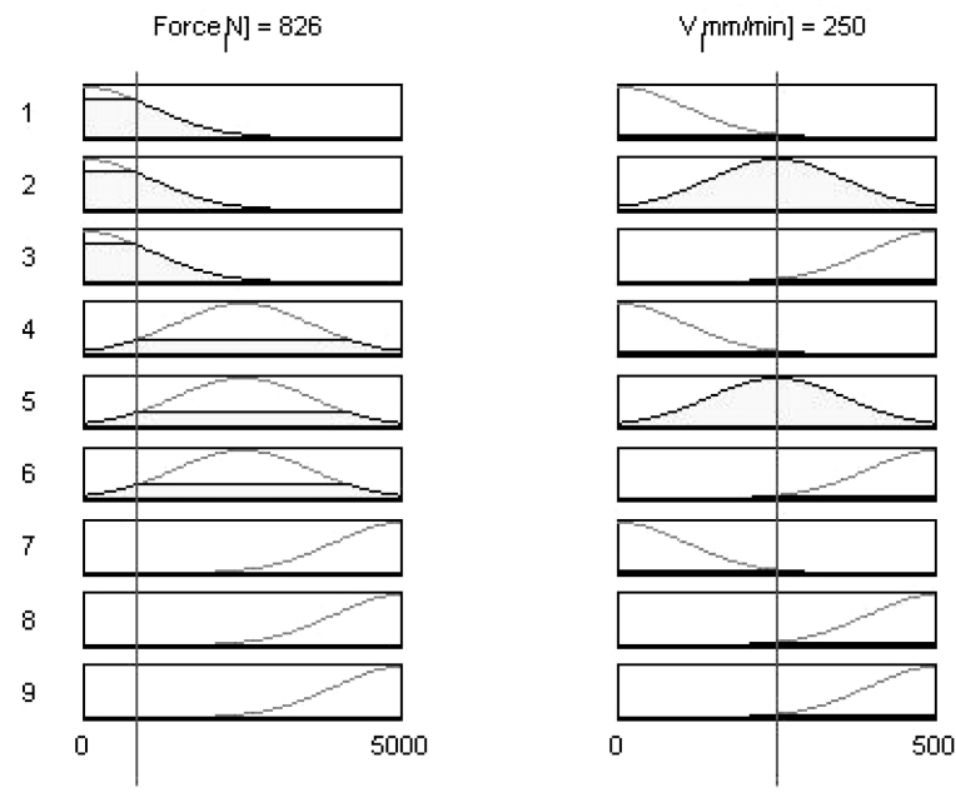

thickness mm] $=0.957$

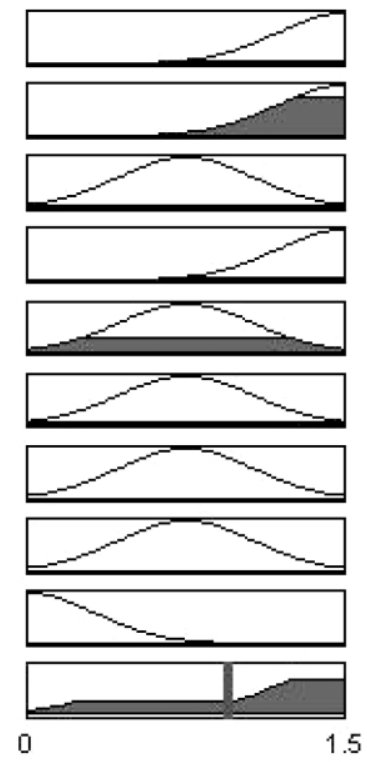

Fig. 9. Schematic representation of the FricExpert fuzzy logic based inference mechanism. 
(now more than 1900), the system is capable of giving expert advice for the next set of experiments, in order to meet various requirements for various quality variables. The value of this system is in reducing the lead time and, hence, cost for determining the optimum parameters for a given coating material on a given substrate geometry. This is an important feature when developing the process for new applications because the optimal process parameters depend on the thermal system, which will vary when materials, mechtrode diameters and substrate geometries are changed. The range of commercial applications of the friction surfacing process currently includes the manufacture of machine knives for the food and pharmaceutical processing/packaging industries. Other applications include hardfacing of valve seats with stellite, the repair and manufacture of parts for the gas turbine industry, notably gas turbine blades, and various types of tooling such as punches and drills.

\section{Conclusions}

1. Measurement and data analysis techniques have been successfully developed for the friction surfacing process.

2. The introduction of the FricExpert Decision Support System has shown to be promising for process parameter selection.

3. Fuzzy rules and membership functions have been established between quality state variables and process parameters, such that they allow for reverse engineering of the optimum friction surfacing process parameters.

\section{References}

[1] E.D. Nicholas, W.M. Thomas, Metal deposition by friction welding, Welding J. August (1986) 17-27.

[2] T. Shinoda, Q. Li, Y. Katoh, T. Yashiro, Effect of process parameters during friction coating on properties of non-dilution coating layers, Surf. Eng. 14 (3) (1998) 211-216.

[3] G.M. Bedford, Friction surfacing for wear application, Metals Mater. 6 (11) (1990) 702-705.

[4] G.M. Bedford, A. Davies, J.R. Sharp, Micro-friction surfacing in the manufacture and repair of gas turbine blades, Third International Charles Parsons Turbine Conference, Newcastle, (1995) 683-693.

[5] G.M. Bedford, R.P. Sharp, B.J. Wilson, L.G. Elias, Production of friction components using steel MMCs produced by the osprey process, Surf. Eng. 10 (2) (1994) 118-122.

[6] G.M. Bedford, V.I. Vitanov, I.I. Voutchkov, Decision support system for the frictec (friction surfacing) process, Proceedings of the Thirteenth National Conference on Manufacturing, Glasgow, UK, 9-11 September 1997, (1997) 580-584.

[7] G.M. Bedford, L.J. Ward, P.J. Tooley, B.J. Wilson, R.J. Sharp, Large scale friction surfacing, EUROMAT'95, Proceedings of the Fourth European Conference on Advanced Materials and Processes, Italy, Sept. 1995, (1995) 441-444.

[8] I.I. Voutchkov, V.I. Vitanov, G.M. Bedford, Neurofuzzy model-based selection of process parameters for friction surfacing applications, Proceedings of the Thirteenth National Conference on Manufacturing, Glasgow, UK, 9-11 September 1997, (1997) 491-495.

[9] S. Chui, Fuzzy model identification based on cluster estimation, J. Intelligent Fuzzy Syst. 2 (3) (1994).

[10] I. Graham, P. Jones, Expert Systems Knowledge, Uncertainty and Decision, Chapman and Hall Computing, 1988.

[11] M. Musen, Automated Generation of Model-Based Knowledge-Acquisition Tools, Pitman, London, 1989.

[12] S. Padney, Computer aided process planning - an expert system approach, computer technology in welding, Proceedings of the Sixth TWI International Conference, 9-12 June, 1996, (1996).

[13] P. Schnupp, C. Nguyen Huu, L. Bernhard, Expert Systems Lab Course, Springer-Verlag, 1989. 